\title{
Optimal Operation of Biomass Gasifier Based Hybrid Energy System
}

\author{
P. Balamurugan, ${ }^{1}$ S. Kumaravel, ${ }^{2}$ and S. Ashok ${ }^{2}$ \\ ${ }^{1}$ MNSK College of Engineering, Pudukkottai, Tamilnadu 622305, India \\ ${ }^{2}$ National Institute of Technology Calicut, Kerala 673601, India \\ Correspondence should be addressed to P. Balamurugan, balapv@yahoo.com
}

Received 23 June 2011; Accepted 2 August 2011

Academic Editors: A. Bosio, S. Dai, and A. Hasan

Copyright (C) 2011 P. Balamurugan et al. This is an open access article distributed under the Creative Commons Attribution License, which permits unrestricted use, distribution, and reproduction in any medium, provided the original work is properly cited.

\begin{abstract}
The focus of the world on renewable energy sources is growing rapidly due to its availability and environment friendliness. However, the renewable energy influenced by natural conditions is being intermittent, it is difficult to accomplish stable energy supply only by one kind of renewable energy source. In order to achieve reliability, it is necessary to integrate two or more energy sources together in an optimal way as hybrid energy system. Optimal allocation of sources, unpredictable load demand, intermittent behaviors of sources, and charging and discharging of storage devices are the major challenges in operating a hybrid energy system. A new controller algorithm is developed and implemented in controller hardware to overcome the above issues. The controller is incorporated in biomass gasifier-based hybrid energy system in a university campus at south India. A case study is carried out in real-time at the site for a typical day. From the experimentation, it is estimated that the annual savings in the operating cost are Rs $375,459.00$ ( $\$ 8475.4)$ for the optimal allocation of the sources by the controller.
\end{abstract}

\section{Introduction}

Depleting oil and gas reserves, combined with growing concerns of atmospheric pollution, have made the search for energy from renewable sources inevitable [1]. They are inexhaustible according to human standards. Large technical potentials are available in most countries and public acceptance is high [2]. Rural households in industrialized and developing countries give importance to a reliable supply of electricity even if its capacity is limited [3].

It is estimated that two billion people in small villages in developing countries currently lack grid-based electricity service. In many cases, grid extension is impractical because of dispersed populations, rugged terrain, or both. Thus, small off-grid stand-alone renewable energy systems represent an important option for narrowing the electricity gap in rural parts of the developing world, where progress in grid extension remains slower than population growth. In isolated areas which are far from the grid, it is really impossible to meet the small power loads either through longdistance distribution network or by means of conventional generation. This can be accounted for high cost of transmission lines and higher transmission losses associated with distribution of centrally generated power to remote areas $[4,5]$.

Renewable energy sources are, in general, a much more dilute form of energy. Several renewable energy sources, notably wind, waves, tidal, and solar are either intermittent by nature or vary greatly according to time of day or season. Storage system or utility grid integration is essential to make the renewable energy system dependable. On the other hand, two or more energy sources can be integrated to give reliable and quality power. Such systems, called hybrid energy systems, overcome limitations inherent in the individual systems [6]. Hybrid energy systems can be with combination of renewable energy systems alone (such as $\mathrm{PV} /$ wind) or with combinations of conventional and renewable energy systems (such as diesel/wind). Various renewable energy sources are available throughout the world. The renewable energy sources are site specific and sensitive to climatic conditions. So the proper selection and sizing of this renewable energy sources are very important in the hybrid energy system. 
There are many combinations of different energy sources and storage devices to build a hybrid energy system [7-10]. The effect of introducing a significant amount of wind generation into an isolated power system consists of several diesel generators is discussed [11]. Feasibility of replacing the diesel generators partly by solar photovoltaic system is discussed. Energy planning in the Brazilian Amazon faces two major challenges [12]. An SPV-diesel system has greater reliability for electricity production than an SPV-only system. This provides greater flexibility, higher efficiency, and lower costs for the same energy quantity produced [13].

Control of hybrid energy system involves several aspects such as monitoring the load demand, state of charge of battery, availability of sources, and optimal allocation of sources. A dedicated controller with suitable control strategy is required to accomplish the above tasks. Several literatures are reported on control of hybrid energy system [14-19].

A microprocessor-based controller to optimize the operation of diesel alternator operating in parallel with a batteryinverter system is designed [14]. Management of the system is based on current system status as well as system constants. Apart from the controlled switching of the sources, the function of the controller is to optimize loading on the diesel alternator. A dedicated microprocessor control system to effectively manipulate a hybrid energy system for efficiently utilizing the available energy is presented. The controller takes care of the life of battery banks [15]. Battery management of PV-based hybrid power systems is discussed [16]. The design of control strategies, their effectiveness, and energy enhancement potential for solar-wind-dieselintegrated energy systems is presented [17]. The controls are provided to energize a diesel engine and obtain a supply from a battery bank when solar and wind energy sources are not available. The diesel generator becomes the source of energy whenever the renewable energy and the energy stored in the battery bank are not available.

A controller to monitor the operation of the autonomous grid-linked system is designed [18]. A novel strategy, optimized by genetic algorithms, to control stand-alone hybrid renewable electrical systems with hydrogen storage, is presented [19]. Rural areas produce enough biomass and agricultural residues so that all their electricity demands can be met by using biomass gasifier-based power plants. A biomass gasifier-based hybrid energy system is proposed in this paper.

It is really complex to envisage the availability of renewable sources of a particular site. In a hybrid energy system, the sources are to be allocated optimally based on the availability of sources and monitoring the charging and discharging of battery. A controller is necessary to coordinate the entire operations of hybrid energy system. Implemented biomass-based hybrid energy system with a digital controller is discussed in this paper.

\section{System Description}

2.1. Modeling of System Components. A biomass gasifier hybrid energy system consisting of biomass gasifiers, solar photovoltaic system with battery bank is modeled as shown below using standard equations. Figure 1 shows the schematic of the hybrid energy system with controller. The power output from the biomass gasifier depends on the lower heating value of the biomass fuel used for gasification. Biomass gasifier efficiency is defined as the ratio of the heat content of the fuel gas generated by the gasification of the wood and of the heat content of that wood when it is totally burnt. The efficiency of biomass gasifier is

$$
\eta_{\text {gasifier }}=\frac{M_{g} \mathrm{LHV}_{g}}{M_{b} \mathrm{LHV}_{b}}
$$

where $M_{g}$ and $M_{b}$ are the masses of gas generated by the gasification and biomass, respectively, $\mathrm{LHV}_{g}$ and $\mathrm{LHV}_{b}$ are the lower heating values of gas generated by the gasification and biomass, respectively.

It is suggested to operate the biomass gasifier system with optimum load to reduce the cost of energy. The operating range of the generator is limited by

$$
E_{G \min } \leq E_{G}(t) \leq E_{G \max },
$$

where $E_{G}$ is the output power of the biomass gasifier.

The hourly output power of PV array is

$$
E_{\mathrm{PV}}=\operatorname{Ins}(t) A \eta_{\mathrm{PV}},
$$

where $E_{\mathrm{PV}}$ is the power from SPV system (W), $\operatorname{Ins}(t)$ is the solar insolation at time $t\left(\mathrm{~W} / \mathrm{m}^{2}\right), A$ is the area of the SPV system $\left(\mathrm{m}^{2}\right)$, and $\eta_{\mathrm{PV}}$ is the efficiency of the SPV system.

The battery bank serves as an energy source entity when discharging and a load when charging. The net energy balance to the battery determines its state-of-charge (SOC). The battery has to be protected against overcharging. It is also necessary to guard the battery against excessive discharge. Therefore, the SOC at any period $t$ should be greater than a specified minimum $\mathrm{SOC}, \mathrm{SOC}_{\mathrm{min}}$

$$
1 \geq \operatorname{SOC}(t) \geq \operatorname{SOC}_{\min } .
$$

2.2. Control Algorithm. A new power conditioning algorithm is proposed and implemented in the microcontroller hardware. Monitoring the load demand, solar insolation, and biomass fuel availability, state of charge of battery and grid availability are the major tasks of the controller apart from optimal allocation of sources. This algorithm is used to control the entire operations of the hybrid energy system effectively. The algorithm checks the availability of solar power, biomass fuel, and state of charge of battery continuously. It also measures the load demand. If the load demand matches the power produced, then the sources are allocated by the controller. After the allocation, excess power, if any, is used for charging the battery bank. The controller allocates battery if the demand cannot be met by the available sources. The two biomass gasifiers are operated optimally based on the load demand. Biomass gasifiers require some time to take up the load demand during startup which is taken care of by the battery. The controller algorithm monitors the shortage or excess power continuously. Then the conditioner interfaces the utility grid with the hybrid 


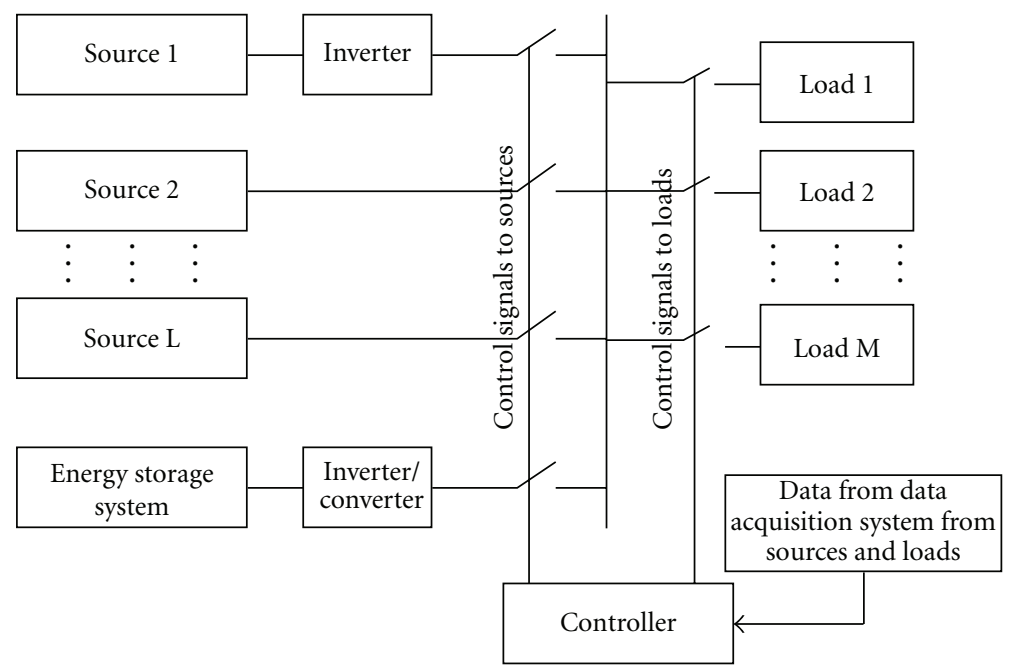

FIGURE 1: Schematic representation of biomass gasifier-based hybrid energy system with controller.

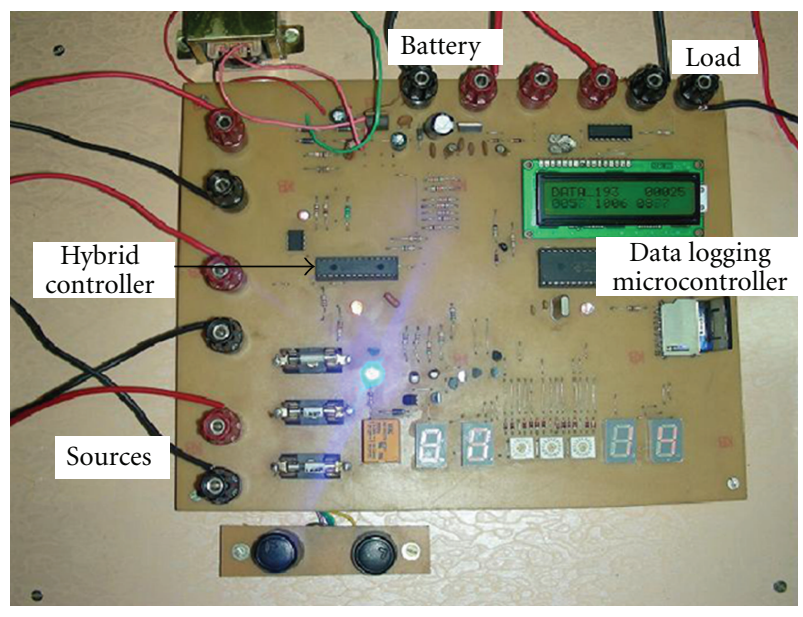

Figure 2: Prototype controller.

energy system to meet the shortage or feed the excess power. For any controller, there are $2^{n}$ allocations possible, where $n$ is the number of source. The controller fetches the solar insolation data from the data logging microcontroller which is interfaced with the environmental monitoring station of the university to get instantaneous solar radiation data continuously. Wind generator is proposed to be integrated with the existing biomass gasifier-based hybrid energy system. The algorithm will take care of the integration of new source with minor modification in the coding.

2.3. Hardware Implementation. The controller is developed using two microcontrollers. Figure 2 shows the prototype hardware with different energy sources connected. One microcontroller is exclusively for controlling the operation of the hybrid energy system and the other is to log the meteorological data such as solar insolation, wind speed data, and fuel availability. The controller algorithm is implemented in a PIC16F873 microcontroller which is the main controller. The data acquisition system in the controller is designed using a PIC18F458 microcontroller with 1 GB memory to log the data. The data acquisition system logs the solar insolation continuously from the environmental monitoring station of the university campus. The logged data can be transferred to computer system for further analysis. The main controller in which the controller algorithm is implemented fetches the solar insolation data from the data acquisition system. Necessary circuitry is provided to measure the load demand and state-of-charge of battery.

The controller controls the allocation of sources through relays by sending the proper control signals depend on the availability of the sources. The controller measures the battery bank voltage using voltage divider circuit and current flow from and to the battery using resistor-shunt circuitry to find the state of charge of battery. The relays are operated by the main microcontroller through relay driver circuits by sending appropriate control signals. In the proposed hardware, there are four such relays to control the operation of the sources and battery apart from grid interfacing. The ultimate aim of the controller design is to utilize the renewable energy sources to the maximum extent. However, the controller will interface the hybrid energy system with the utility grid to draw or feed power during shortage and excess power in the hybrid energy system.

\section{Case Study}

A biomass gasifier-based hybrid energy system consists of two biomass gasifiers, SPV system and battery bank along with the developed controller are implemented in a university campus in south India. Figure 3 shows the biomass gasifiers and SPV systems of the university. Utility grid supply is already available at the site. This hybrid energy system is implemented to reduce the demand of the utility grid. The annual average demand of the campus is $4000 \mathrm{kWh}$ per day with a peak demand of $295 \mathrm{~kW}$. Figure 4 shows the 

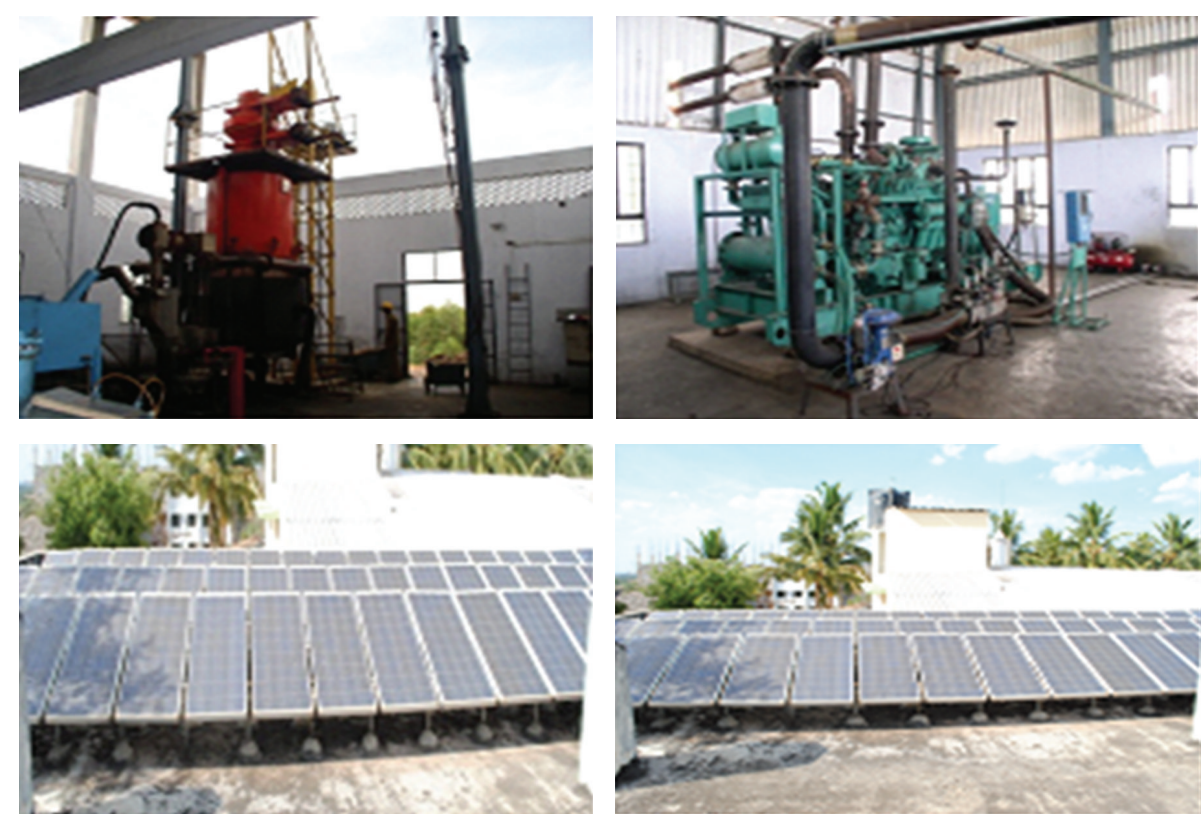

FIGURE 3: Biomass gasifier and solar photovoltaic system.

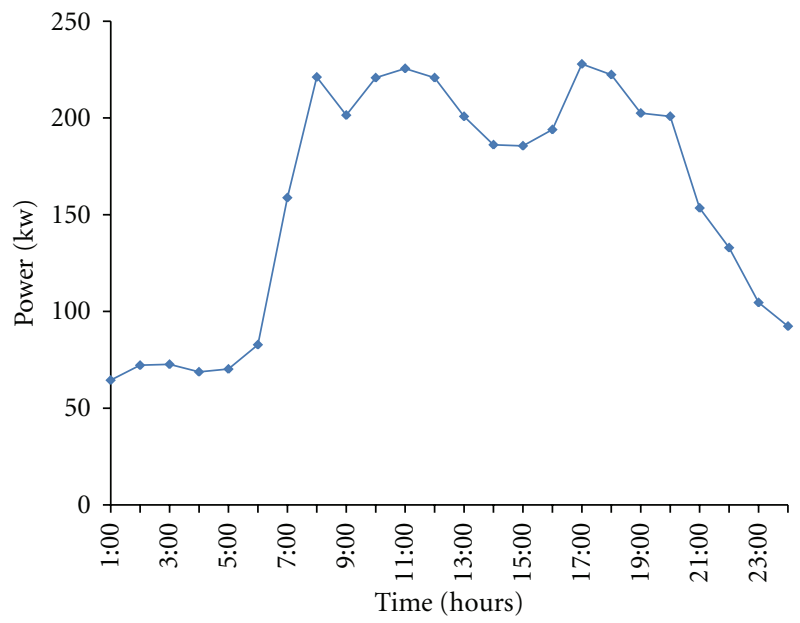

FIgURE 4: Load demand for a typical day.

load demand for a typical day. Table 1 shows the ratings and parameters of the hybrid energy system.

This site has an average solar irradiation of $5.4 \mathrm{~kW} / \mathrm{m}^{2} /$ day. Biomass is available in abundance at the site. The biomass materials that have been used for power generation include rice husk, cotton stalk, mustard stalk, Prosopis juliflora (Vilayati babul), poultry litter, and bagasse. The calorific value is $4000 \mathrm{~kJ} / \mathrm{kg}$. Biomass gasification converts solid biomass into more convenient gaseous form. This process is done in gasifier mainly comprised of a reactor, where the combustible gas is generated and the gas is made available for power generation/thermal application after the required cleaning and cooling process.

Using this gas, it is possible to operate a diesel engine on dual fuel mode with marginal changes to the air inlet or
TABLE 1: Ratings and parameters of the hybrid energy system.

\begin{tabular}{lcc}
\hline \multirow{2}{*}{ SPV system } & Capacity & $8 \mathrm{~kW}, 400 \mathrm{~V}$ \\
& Size of SPV panel & $1341 \mathrm{~mm} \times 990 \mathrm{~mm} \times$ \\
& Overall efficiency & $36 \mathrm{~mm}$ \\
& Capacity & $200 \mathrm{~kW}, 400 \mathrm{~V}$ \\
\hline \multirow{2}{*}{ Biomass gasifier1 } & Minimum loading & $30 \%$ \\
\hline \multirow{2}{*}{ Biomass gasifier2 } & Capacity & $100 \mathrm{~kW}, 400 \mathrm{~V}$ \\
& Minimum loading & $30 \%$ \\
\hline \multirow{2}{*}{ Battery bank } & $12 \mathrm{~V}, 200 \mathrm{AH}$ & $80 \mathrm{numbers}$ \\
& Minimum & $40 \%$ \\
\hline
\end{tabular}

in a $100 \%$ producer gas engine. In dual fuel mode, diesel substitution of the order of 80 to $85 \%$ can be obtained at nominal loads. The recent developments have made possible the operations of spark-ignited gas engine using gas alone. An alternator is coupled with the engine for electrical power generation, either for local consumption or for grid synchronization.

To demonstrate the biomass gasifier-based hybrid energy system and the implemented controller, a site test is conducted for a typical day. Figure 5 shows the hourly solar insolation and the calculated power from solar photovoltaic system at the site. Necessary measuring and monitoring equipments are connected to the controller and to the hybrid energy system to monitor the power from the sources, load demand, state-of-charge of battery, and control signals of the controller. Different operations of the controller have been observed and the results are presented.

During the site testing, hybrid energy system has not been interfaced with the utility grid since the utility grid 


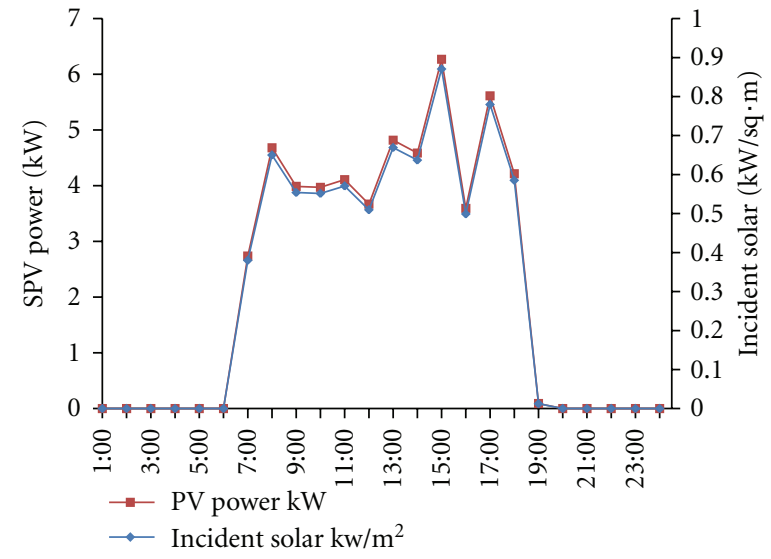

Figure 5: Hourly solar radiation and solar power at the site.

does not accept the operating voltage of the hybrid system $(400 \mathrm{~V})$. But the controller algorithm has been programmed to interface with the utility grid. Hourly load demand and meteorological data have been recorded for one year for the site. Economic analysis has been carried out using the micropower optimization software Homer, developed by National Renewable Energy Laboratory, USA, with the data.

\section{Results and Discussion}

From the site test conducted, various functions of the controller were monitored with the biomass gasifier-based hybrid energy system. Figure 6 depicts the allocation of sources under different conditions by the controller for a typical day. It is found that how the sources were allocated according to the load demand and availability. The entire operations of the controller can be seen from Figure 6. It shows that the power from SPV is fully utilized to supply the load demand as well as charging the battery during day times.

The charging and discharging of the battery bank is also shown. It was observed that the controller utilized the battery bank effectively. Controller switches the batteries into charging mode whenever excess power available from the sources after allocating to the load demand. It was in discharging mode, whenever there was a shortage of power from sources. From Figure 6, it is found that the maximum demand of $221 \mathrm{~kW}$ which occurs at 8:00 am is met by all the energy sources. During that time, excess power available from the hybrid energy system is used for charging the battery bank. The controller turns off one of the biomass gasifier when the load demand can be met by the SPV, any one of the biomass gasifier and battery bank.

For example on the typical day, at 15 hours the load demand is only $185 \mathrm{~kW}$, the controller allocates $100 \mathrm{~kW}$ biomass gasifier, SPV, and battery bank to supply the energy to the load without allocating the $200 \mathrm{~kW}$ biomass gasifier. During the day of the real-time site test, the controller allocated the two biomass gasifiers optimally. The demand was met by the hybrid energy sources along with the battery bank. Table 2 shows the contributions of the two biomass gasifiers in the hybrid energy system. The annual operating

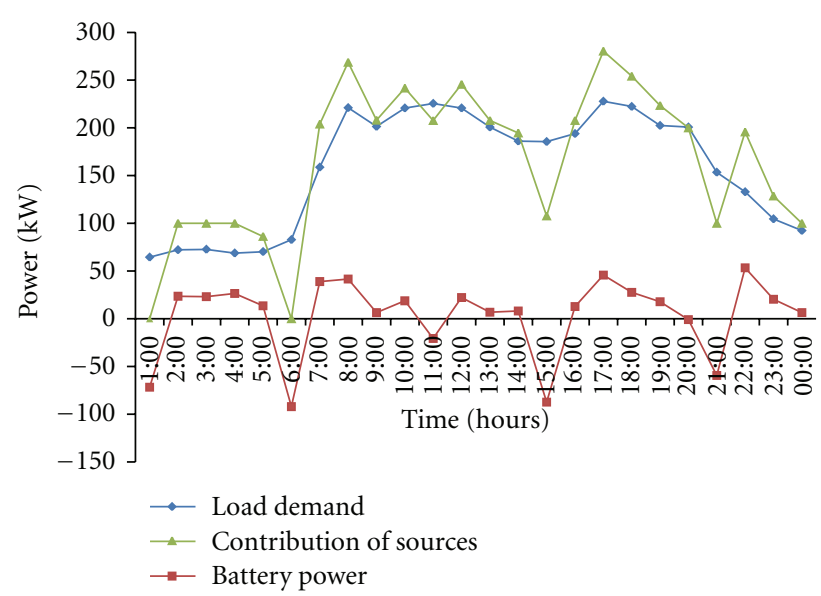

FIgURE 6: Optimal allocation sources by the controller.

TABle 2: Contributions of the two biomass gasifiers in the hybrid energy system.

\begin{tabular}{lcc}
\hline Quantity & $\begin{array}{c}\text { 200 kW biomass } \\
\text { gasifier }\end{array}$ & $\begin{array}{c}100 \mathrm{~kW} \text { biomass } \\
\text { gasifier }\end{array}$ \\
\hline Hours of operation (hr/yr) & 4,582 & 5,807 \\
Number of starts & 1,223 & 2,236 \\
Operational life (year) & 17.5 & 13.8 \\
Capacity factor (\%) & 50.6 & 57.3 \\
$\begin{array}{l}\text { Electrical production } \\
\text { (kWh/yr) }\end{array}$ & 887,302 & 501,867 \\
Mean electrical output $(\mathrm{kW})$ & 194 & 86.4 \\
Min electrical output $(\mathrm{kW})$ & 120 & 30 \\
$\begin{array}{l}\text { Max electrical output }(\mathrm{kW}) \\
\text { Biomass consumption }\end{array}$ & 200 & 100 \\
(tonne/yr) & 1,564 & 991 \\
$\begin{array}{l}\text { Specific fuel consumption } \\
\text { (kg/kWh) }\end{array}$ & 1.322 & 1.481 \\
\hline
\end{tabular}

hours and the number of starts are also shown in the Table 2. The mean, maximum, and minimum power generated by the two biomass gasifiers and the number of starts are also mentioned in the Table 2. The specific fuel consumption of the $200 \mathrm{~kW}$ biomass gasifier is $1.322 \mathrm{~kg} / \mathrm{kWh}$ but the specific fuel consumption of the $100 \mathrm{~kW}$ gasifier is $1.481 \mathrm{~kg} / \mathrm{kWh}$.

\section{Economic Analysis}

Figure 7 shows the annual contribution of the sources in hybrid energy system. It shows that the SPV system contributes $18,718 \mathrm{kWh}$ of energy which is about $1 \%$ of the total energy supplied to the load by the hybrid energy system. The $200 \mathrm{~kW}$ biomass gasifier contributes $887,302 \mathrm{kWh}$ which is about $59 \%$ of the total energy supplied to the load by the hybrid energy system. The $100 \mathrm{~kW}$ biomass gasifier contributes about $501,867 \mathrm{kWh}$ which is about $33 \%$ of the total energy supplied to the load by the hybrid energy system. The energy shortage is 106,581 which is $7 \%$ of the total annual demand. 
TABLE 3: Comparison of systems with and without hybrid operation and controller.

\begin{tabular}{lcccc}
\hline \multirow{2}{*}{ Source } & \multicolumn{2}{c}{ With hybrid operation and with controller } & \multicolumn{2}{c}{ Without hybrid operation and controller } \\
& Operating time (hours) & Operating cost (Rs) & Operating time (hours) & Operating cost (Rs) \\
\hline Biomass gasifier $(200 \mathrm{~kW})$ & 4,582 & $1,518,933$ & 5745 & $1,904,467$ \\
Biomass gasifier $(100 \mathrm{~kW})$ & 5,807 & 943,637 & 5745 & 933,562 \\
\hline Total & & $\mathbf{2 , 4 6 2 , 5 7 0}$ & $\mathbf{2 , 8 3 8 , 0 3 0}$ \\
\hline
\end{tabular}

TABLE 4: Economic detail of the proposed wind generator (4 numbers $\times 30 \mathrm{~kW}$ each).

\begin{tabular}{lc}
\hline Capital & $12,000,000(\$ 270,880.36)$ \\
Operation and maintenance & $4,587,971(\$ 103,565.94)$ \\
Total & $16,587,972(\$ 374446.3)$ \\
\hline
\end{tabular}

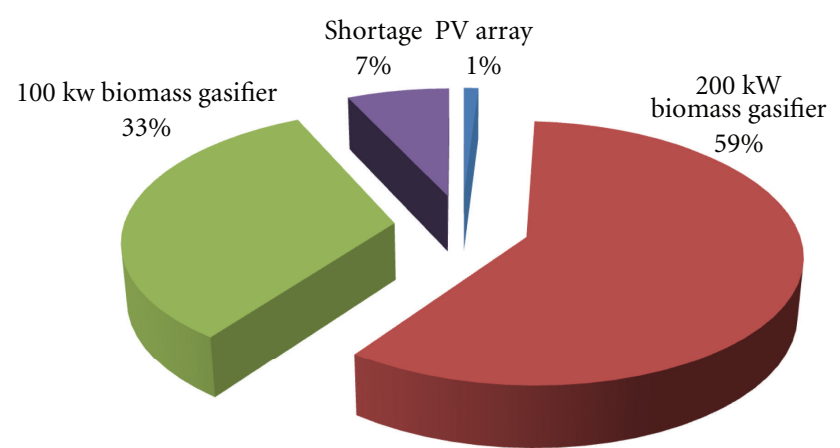

FIGURE 7: Annual contribution of different sources and shortage.

The two biomass gasifiers and SPV systems are feeding separate wings of the university. Usually the gasifiers are operated during day times, from 6:00 AM to 9:00 PM (15 hours per day). Utility grid supplies the power during night times. With the hybrid operation and implementation of controller, it is estimated that there is a considerable saving in the operating costs of the biomass gasifiers. Table 3 shows the comparison of operating costs. The annual estimated savings in operating cost are Rs 375,459 (\$8475.37).

A simulation is carried out using HOMER, a micropower optimization software, to add the optimal sizes of the sources with the existing biomass gasifier-based hybrid energy system. The simulation results show optimal sizes of the sources which are presented in Table 4 considering the future expansion of load demand. The daily average demand is projected as $4500 \mathrm{kWh}$ per day and the new wind generator is integrated to meet the load demand without any shortage. Simulation results show that four numbers of $30 \mathrm{~kW}$ wind generator is to be integrated to the existing system.

\section{Conclusion}

A controller algorithm for the optimal control and operation of the hybrid energy system is developed. The developed controller is implemented in a hybrid system consists of two biomass gasifiers, SPV system and battery in a university campus. Real time site test is conducted for a typical day.
It is found that the implemented algorithm allots the sources effectively and the hybrid energy system supplies the demand of the particular site effectively. The two biomass gasifiers and SPV systems are feeding separate wings of the university. With the hybrid operation and implementation of controller, it is estimated that there is a considerable saving in the operating costs of the biomass gasifiers. The annual estimated savings in operating cost of Rs 375,459 (\$8475.37) show the effectiveness of the controller and hybrid operation.

\section{References}

[1] M. A. Elhadidy and S. M. Shaahid, "Promoting applications of hybrid (wind+photovoltaic+diesel+battery) power systems in hot regions," Renewable Energy, vol. 29, no. 4, pp. 517-528, 2004.

[2] S. Espey, "Renewables portfolio standard: a means for trade with electricity from renewable energy sources?" Energy Policy, vol. 29, no. 7, pp. 557-566, 2001.

[3] B. Wichert, "PV-diesel hybrid energy systems for remote area power generation-a review of current practice and future developments," Renewable and Sustainable Energy Reviews, vol. 1, no. 3, pp. 209-228, 1997.

[4] C. D. Barley and C. B. Winn, "Optimal dispatch strategy in remote hybrid power systems," Solar Energy, vol. 58, no. 4-6, pp. 165-179, 1996.

[5] J. Byrne, B. Shen, and W. Wallace, "The economics of sustainable energy for rural development: a study of renewable energy in rural China," Energy Policy, vol. 26, no. 1, pp. 45-54, 1998.

[6] G. Tina, S. Gagliano, and S. Raiti, "Hybrid solar/wind power system probabilistic modelling for long-term performance assessment," Solar Energy, vol. 80, no. 5, pp. 578-588, 2006.

[7] E. S. Abdin, A. M. Osheiba, and M. M. Khater, "Modeling and optimal power conditioners design for a stand-alone photovoltaic-diesel generating unit," IEEE Transactions on Energy Conversion, vol. 14, no. 3, pp. 560-565, 1999.

[8] R. W. Wies, R. A. Johnson, A. N. Agrawal, and T. J. Chubb, "Simulink model for economic analysis and environmental impacts of a PV with diesel-battery system for remote villages," IEEE Transactions on Power Systems, vol. 20, no. 2, pp. 692700, 2005.

[9] Á. Lentz and R. Almanza, "Solar-geothermal hybrid system," Applied Thermal Engineering, vol. 26, no. 14-15, pp. 15371544, 2006.

[10] A. R. Prasad and E. Natarajan, "Optimization of integrated photovoltaic-wind power generation systems with battery storage," Energy, vol. 31, no. 12, pp. 1943-1954, 2006.

[11] S. S. Choi and R. Larkin, "Performance of an autonomous diesel-wind turbine power system," Electric Power Systems Research, vol. 33, no. 2, pp. 87-99, 1995. 
[12] A. L. Schmid and C. A. A. Hoffmann, "Replacing diesel by solar in the Amazon: short-term economic feasibility of PVdiesel hybrid systems," Energy Policy, vol. 32, no. 7, pp. 881898, 2004.

[13] M. Muselli, G. Notton, and A. Louche, "Design of hybrid-photovoltaic power generator, with optimization of energy management," Solar Energy, vol. 65, no. 3, pp. 143-157, 1999.

[14] W. B. Lawrance, C. V. Nayar, T. L. Pryor, and S. J. Phillips, "Microprocessor control of a hybrid energy system," in Proceedings of the 24th Intersociety Energy Conversion Engineering Conference (IECEC’ 89), pp. 737-741, August 1989.

[15] H. A. van der Linde and I. Clark, "Microprocessor control of hybrid energy systems," in Proceedings of the 3rd AFRICON Conference (AFRICON'92), pp. 217-220, 1992.

[16] T. D. Hund and S. Gates, "PV hybrid system and battery test results from Grasmere Idaho," in Proceedings of the 29th IEEE Photovoltaic Specialists Conference, pp. 1424-1427, New Orleans, La, USA, May 2002.

[17] K. Thyagarajan, R. P. Mandi, R. S. Kumar, and M. Siddhartha Bhatt, "Enhancing energy generation by use of efficient control for hybrid energy systems," Applied Energy, vol. 52, no. 2-3, pp. 255-263, 1995.

[18] R. Chedid and S. Rahman, "Unit sizing and control of hybrid wind-solar power systems," IEEE Transactions on Energy Conversion, vol. 12, no. 1, pp. 79-85, 1997.

[19] R. Dufo-López, J. L. Bernal-Agustín, and J. Contreras, “Optimization of control strategies for stand-alone renewable energy systems with hydrogen storage," Renewable Energy, vol. 32, no. 7, pp. 1102-1126, 2007. 

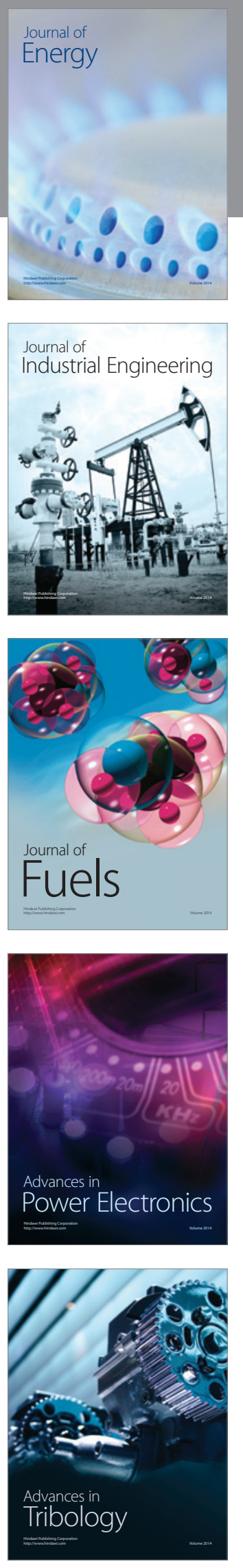
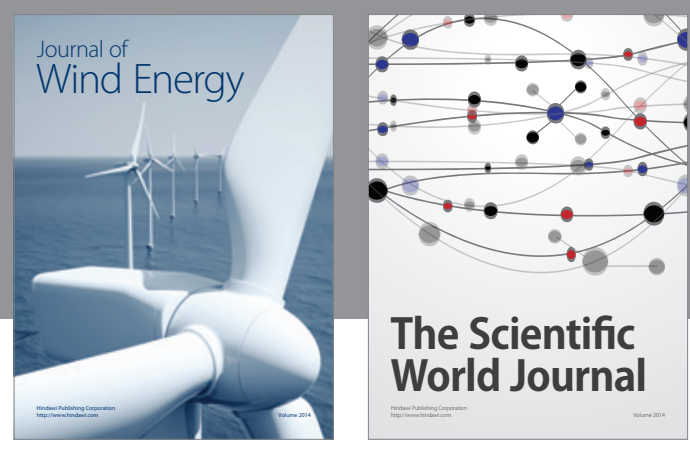

The Scientific World Journal

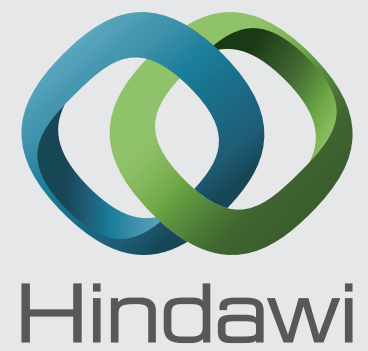

Submit your manuscripts at http://www.hindawi.com
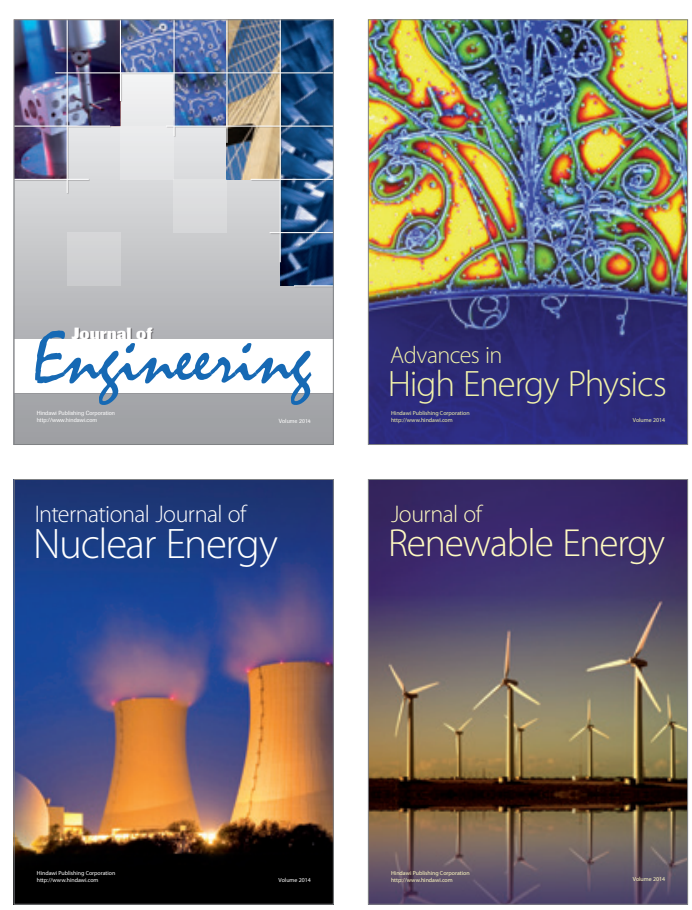

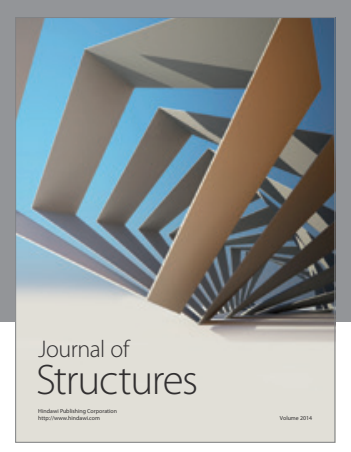

Rotating
Mechinery
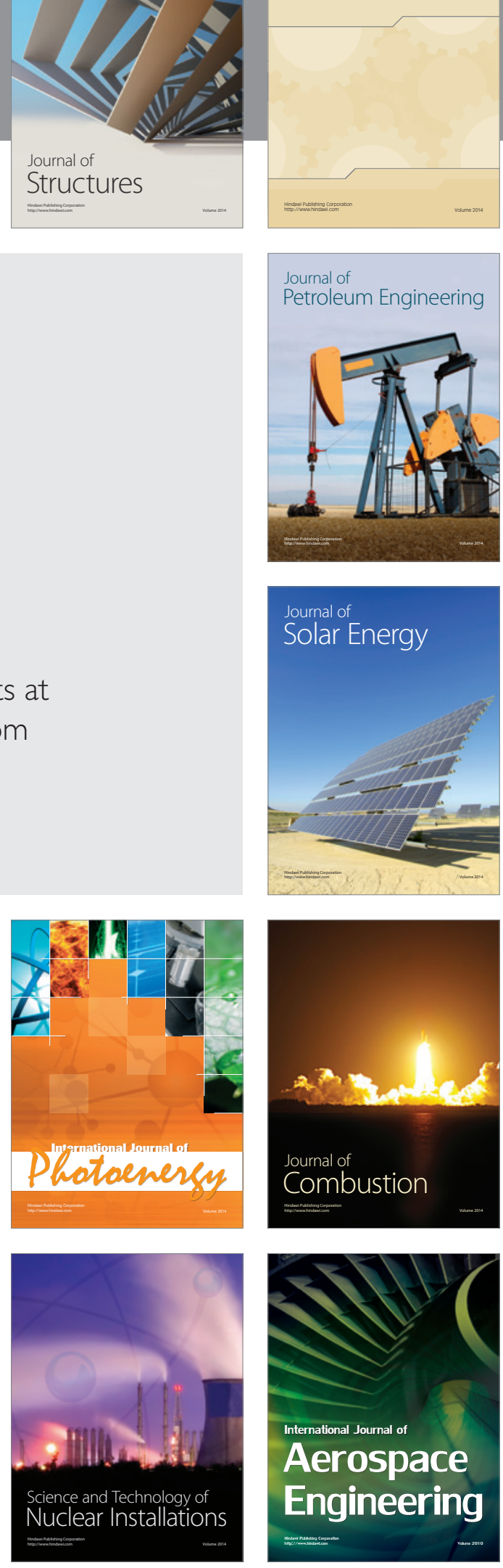